\title{
Mechanisms of edema formation after intracerebral hemorrhage: effects of thrombin on cerebral blood flow, blood-brain barrier permeability, and cell survival in a rat model
}

Kevin R. Lee, M.D., Nobuyuki Kawai, M.D., Seoung Kim, B.A., Oren Sagher, M.D., and Julian T. Hoff, M.D.

Department of Surgery (Neurosurgery), University of Michigan, Ann Arbor, Michigan; and Department of Surgery, Wayne State University, Detroit, Michigan

Recently, the authors showed that thrombin contributes to the formation of brain edema following intracerebral hemorrhage. The current study examines whether the action of thrombin is due to an effect on cerebral blood flow (CBF), vasoreactivity, blood-brain barrier (BBB) function, or cell viability. In vivo solutions of thrombin were infused stereotactically into the right basal ganglia of rats. The animals were sacrificed 24 hours later; $\mathrm{CBF}$ and $\mathrm{BBB}$ permeability were measured. The actions of thrombin on vasoreactivity were examined in vitro by superfusing thrombin on cortical brain slices while monitoring microvessel diameter with videomicroscopy. In separate experiments C6 glioma cells were exposed to various concentrations of thrombin and lactate dehydrogenase release, a marker of cell death, was measured. The results indicate that thrombin induces BBB disruption as well as death of parenchymal cells, whereas $\mathrm{CBF}$ and vasoreactivity are not altered. The authors conclude that cell toxicity and BBB disruption by thrombin are triggering mechanisms for the edema formation that follows intracerebral hemorrhage.

Key Words * intracerebral hemorrhage * thrombin * blood-brain barrier permeability * cerebral blood flow * C6 glioma cells * brain edema * rat

Understanding the effects of an intracerebral hematoma on brain physiology is critical to developing rational management protocols. Both spontaneous and traumatic hematomas result in surrounding cell injury and brain edema. Increasing amounts of edema following intracerebral hemorrhage often result in worsening neurological function and brain herniation. Preventing the accumulation of edema fluid is therefore an important aspect of management.

The specific mechanism for brain edema formation that follows intracerebral hemorrhage has not been determined. Hemorrhage into the brain initially results in mass effect with local reduction in cerebral blood flow (CBF), but not necessarily to ischemic levels. Edema fluid begins to accumulate several hours later before the blood-brain barrier (BBB) opens and then increases over the first 24 hours.[32]

Mass-related effects on $\mathrm{CBF}$ have been proposed to explain brain injury due to hematomas. Experimentally, however, mass effect alone from an average-sized hematoma has not been shown to 
result in sufficient global or local levels of hypoperfusion to cause cerebral infarction. More recently, a toxic effect of the clot itself has been implicated in the pathogenesis of intracerebral hematomas. We have demonstrated that thrombin, an essential component in the coagulation cascade, is directly involved in the process of brain edema formation following intracerebral hemorrhage (ICH).[14-17]

For a substance to be identified as a neurotoxic mediator, certain requirements must be met.[18] First, the compound must be shown to injure cerebral tissue. Second, formation or activation of the substance must be demonstrated in brain following injury, and the extent of activation must correlate with the extent of brain injury. Third, inhibition of activation or formation of the compound must inhibit or attenuate the amount of injury.

Data from earlier experiments demonstrate that thrombin meets all three criteria for classification as a neurotoxic mediator compound. First, we have shown that thrombin is toxic to the brain, resulting in edema formation following infusion into the basal ganglia.[14,15] Research on coagulation has documented the formation of thrombin following hemorrhage.[24, 29] Although thrombin is not present in measurable amounts in circulating blood, this final-stage protease in the coagulation cascade is produced in relatively large amounts in coagulated blood. Second, we have shown that the degree of conversion of prothrombin to thrombin in a clot correlates with the amount of brain edema around the hematoma.[16] Third, brain edema formation following ICH can be significantly attenuated by thrombin-specific inhibitors.[16,17] Activation of the coagulation cascade with release of thrombin during clotting, therefore, appears to be the triggering event that initiates formation of brain edema.

Our research has shown that brain edema forms in response to thrombin even without fibrin clot formation.[15] Fibrinogen, which is converted to fibrin clot through the enzymatic action of thrombin, does not affect the amount of edema produced by thrombin; therefore, the mechanism of edema formation does not involve the release of fibrinopeptides or fibrin degradation products. We have also shown that whole blood produces more brain edema than plasma or red blood cells alone.[16] Prothrombinase, the enzyme complex that produces thrombin, has cofactors located in both the plasma component and the cellular component of blood. Factor V, factor X, and calcium from plasma, as well as phospholipids from cell membranes, all serve as cofactors that individually accelerate the conversion of prothrombin to thrombin. In whole blood, each of the cofactors is present; therefore, thrombin production and brain edema formation are maximal.

The pathophysiological effects of thrombin that account for brain injury and edema formation have not been elucidated. Brain edema from ICH and thrombin release may be due to ischemia, opening of the $\mathrm{BBB}$, or direct toxicity to brain cells. In this study, $\mathrm{CBF}$, microvessel diameter, BBB permeability, and brain cell survival were measured in tissue exposed to concentrations of thrombin consistent with intracerebral hemorrhage to clarify the events surrounding edema formation in the brain following ICH.

\section{MATERIALS AND METHODS}

\section{Animal Preparation}

A total of 81 male Sprague-Dawley rats, each weighing between 250 and $350 \mathrm{~g}$, were used in experiments of $\mathrm{CBF}$ and $\mathrm{BBB}$ permeability. The rats were anesthetized in a closed chamber with $5 \%$ isoflurane. A catheter was inserted into the trachea by the oral route. The rats were ventilated with a Harvard rodent ventilator using a mixture of oxygen (21\%), nitrogen $(76 \%-77 \%)$, and isoflurane $(2 \%-3 \%)$. Body temperature was maintained at $37.5 \check{\mathrm{s}} \mathrm{C}$ using a rectal thermometer and a 
feedback-controlled heating pad.

\section{Experimental Model}

The rat was positioned in a stereotactic frame and the scalp was incised along the sagittal midline. An operating microscope was used for the remainder of the procedure, and hemostasis was maintained with bipolar electrocautery. A 1-mm burr hole was placed in the skull near the right coronal suture $3 \mathrm{~mm}$ lateral to the midline. A 26-gauge needle was inserted into the right basal ganglia under stereotactic guidance (coordinates; $0.2 \mathrm{~mm}$ anterior, $6 \mathrm{~mm}$ ventral, and $3 \mathrm{~mm}$ lateral to the bregma).[22] Solutions containing $10 \mathrm{U}$ of thrombin in $10 \mu \mathrm{l}$ saline were infused into the brain over a period of 1 minute using a Harvard pump. This represented the amount of thrombin produced by a typical intracerebral hematoma. An average-sized intracerebral hematoma in humans is $54 \mathrm{ml}$, which is approximately a $50-\mu \mathrm{l}$ hematoma in the rat.[28] A range of 260 to $360 \mathrm{U}$ prothrombin are present in $1000 \mu \mathrm{l}$ of plasma.[24] Because a $50-\mu \mathrm{l}$ blood clot contains approximately $30 \mu \mathrm{l}$ plasma, the potential amount of thrombin produced in this size clot was calculated to be $10 \mathrm{U}$.

The stereotactic needle was removed after infusion of solution. The incision was sutured closed. The inhalational anesthetic was discontinued and the animals were extubated. Rats were allowed to recover and given free access to food and water.

\section{Cerebral Blood Flow}

Cerebral blood flow was measured by means of the indicator-fractionation technique using a radioisotope with essentially complete blood-to-brain influx.[26] The method is based on the concept of an "artificial organ" perfused by the femoral artery catheter. A constant rate of blood withdrawal from the cannula represents the blood flow to this organ. At the completion of the experiment, the amount of radioactivity in the blood collected from the femoral artery is equal to the radioactivity of the "artificial organ," and a standard ratio of blood flow to tissue radioactivity can be derived. Measuring the radioactivity of various regions of brain tissue allows a determination of focal $\mathrm{CBF}$ using this relationship.

The animals were anesthetized with 5\% isoflurane, intubated, and ventilated as previously described. Catheters were inserted into the right femoral artery and vein. Arterial blood was withdrawn from the femoral artery at a constant rate. Five seconds after the initiation of the withdrawal, $10 \mu \mathrm{Ci}$

4-(N-methyl-14C) iodoantipyrene in $100 \mu \mathrm{l}$ saline was injected through the venous catheter. Ten seconds after administration of this isotope, the animals were decapitated and the withdrawal of the arterial blood was simultaneously stopped. The withdrawn blood was recovered and $20-\mu l$ aliquots were placed in scintillation vials.

The brain was removed, and a coronal slice $3 \mathrm{~mm}$ from the frontal pole was cut approximately $4 \mathrm{~mm}$ thick and both the ipsilateral and contralateral samples were weighed. The samples of blood and brain tissue were digested in methylbenzethonium hydroxide at $60 \check{\mathrm{s}} \mathrm{C}$ and the samples bleached with hydrogen peroxide.

Liquid scintillation cocktail (Cytoscint) was added to each vial and the radioisotope content of the blood and tissue samples was determined using a two-channel scintillation counter. The blood flow (ml/100 $\mathrm{g} /$ minute) for the brain samples was calculated using the equation: $\mathrm{Fb} / \mathrm{Mb}=\mathrm{Qb}(\mathrm{T}) \mathrm{Fs} / \mathrm{Qs}(\mathrm{T}) \mathrm{Mb} * 100$, where $\mathrm{Fb}=$ cerebral blood flow; $\mathrm{Mb}=$ brain mass; $\mathrm{Qb}(\mathrm{T})=$ quantity of indicator present in the tissue at time $\mathrm{T}$; Fs $=$ rate of blood withdrawal into the syringe from $\mathrm{t}=0$ to $\mathrm{t}=\mathrm{T}$; and $\mathrm{Qs}(\mathrm{T})=$ quantity of indicator present in the cannula at time $\mathrm{T}$. 


\section{Microvessel Diameter}

In vitro brain slices were obtained from rats and examined using computerized videomicroscopy with the methods described previously.[23]

Briefly, rats were anesthetized and perfused with $50 \mathrm{ml}$ buffered saline followed by $10 \mathrm{ml}$ of $0.05 \%$ indigo carmine in saline. Each animal was decapitated and its brain was rapidly removed. Brain slices were cut at a thickness of 300 to $500 \mu \mathrm{m}$ with a tissue chopper and placed in artificial cerebrospinal fluid (CSF) ( NaCl $124.1 \mathrm{mM}$, NaHCO3 25.7 mM, KCl 3.3 mM, KH2PO4 1.3 mM, MgSO4 2.4 mM, CaCl2 2 $\mathrm{mM}$, glucose $10 \mathrm{mM}$ ) in a holding chamber oxygenated with moist 95\% O2/5\% CO2 at 30š C.

Individual slices were mounted in a recording chamber on a transmission microscope and superfused at a constant rate with artificial CSF at $32 \check{s} \mathrm{C}$. While in the recording chamber a vessel was selected and monitored continuously with a light microscope equipped with a CCD camera and a digital image analysis system. Microvessel diameter within the slice was monitored for 10 minutes while the slides were superfused with artificial CSF. Thrombin in artificial CSF was then allowed to superfuse the slices for 50 minutes while the microvessel diameter was monitored.

Because thrombin has been shown to cause release of endothelin, which has an immediate vasoconstrictive effect, we were interested in rapid vascular changes due to endothelin or the direct effects on the vascular smooth-muscle cells. An observation period of 1 hour was therefore adequate for these recordings. Previous studies using this system have shown that vascular responsiveness is retained in the brain slice preparation, as evidenced by constriction of microvessels due to potassium, endothelin, and phorbol dibutyrate.[23]

\section{Blood-Brain Barrier Permeability}

Blood-brain barrier permeability was measured in vivo at 24 hours after intracerebral infusion of thrombin or saline using an amino acid analog, alpha-aminoisobutyric acid (AIB), which is ordinarily not transported into the brain. The method has been previously described.[2] A radioisotope of inulin, a molecule that remains intravascular despite breakdown of the BBB, was used to measure intravascular volume.

The rats that had received intracerebral infusions of thrombin or saline 24 hours earlier were anesthetized with ketamine $(10 \mathrm{mg} / \mathrm{kg})$ and xylazine $(50 \mathrm{mg} / \mathrm{kg})$, and catheters were placed in both femoral arteries and one femoral vein.

The rats received a bolus injection of [3H]-AIB $(25 \mu \mathrm{Ci})$, and arterial blood was withdrawn at a constant rate $(1 \mathrm{ml} /$ minute) using a peristaltic pump. Eight minutes later the rats received an intravenous injection of [14C]-inulin $(15 \mu \mathrm{Ci})$, which was allowed to circulate for 2 minutes before a terminal arterial sample was obtained and the rats were decapitated. The brain and arterial samples were processed as described for the $\mathrm{CBF}$ measurements, and the radioisotope content of both blood and tissue samples was determined using a two-channel scintillation counter.

For compounds of low permeability such as AIB, the influx rate constant $(\mathrm{K} 1)$ can be calculated as: $\mathrm{K} 1=$ $\operatorname{Cev}(\mathrm{T}) /($ integral)Cadt, where $\operatorname{Cev}(\mathrm{T})$ is the extravascular concentration of isotope at time $\mathrm{T}$ and (integral)Cadt is the integral of the arterial tracer concentration from time 0 to time T. Cev(T) was calculated from the total tracer counts $\operatorname{Ctot}(\mathrm{T})$ in brain samples, final tracer plasma concentration $\mathrm{Cpl}(\mathrm{T})$ and the plasma volume PV: $\operatorname{Cev}(\mathrm{T})=\operatorname{Ctot}(\mathrm{T})-(\mathrm{PV} * \mathrm{Cpl}(\mathrm{T}))$. 


\section{Cell Culture}

Cells from the C6 rat glioma line were cultured in $25 \mathrm{sq} \mathrm{cm}$ polystyrene flasks containing $15 \%$ (vol/vol) horse serum, $5 \%$ (vol/vol) fetal bovine serum, and 80\% (vol/vol) Dulbecco's minimal essential medium. Penicillin G sodium (100,000 U/L), streptomycin sulfate (100,000 U/L) and the antimycotic agent, amphotericin B $(25000 \mu \mathrm{g} / \mathrm{L})$ were added. The media contained $2 \mathrm{mM}$ glutamine and $1 \mathrm{mM}$ sodium pyruvate. The cultures were grown in a controlled environment with 5\% $\mathrm{CO} 2$ and $95 \%$ atmospheric air at 37.2 š C. The cells were passaged after they reached $90 \%$ confluency every 2 to 3 days. Sterile-filtered trypsin-ethylenediamine tetra acetic acid was used to detach cells from the flask surface.

Cells were removed from flasks with confluent cell layers as follows. After the old media was discarded, $5 \mathrm{ml}$ of fresh media was added to the flask and then withdrawn. This cell-rich fluid was added to $19 \mathrm{ml}$ of media. One milliliter of this solution was then pipetted into individual wells of a plate.

Thrombin was then added to the wells to give total concentrations of $0,1,10$, and $100 \mathrm{U}$ thrombin per milliliter in each well.

Twenty-four hours later, $50-\mu \mathrm{l}$ aliquots were pipetted from each well and stored frozen (-20š C) for later determination of lactate dehydrogenase (LDH) activity. This enzyme is released with cell lysis and is a marker of membrane integrity. The amount of LDH efflux in cell cultures correlates in a linear fashion to the number of brain cells damaged.[11]

\section{Lactate Dehydrogenase Assay}

Lactate dehydrogenase concentrations were measured using a commercially available diagnostic kit. One milliliter of $0.75 \mathrm{mmol} / \mathrm{L}$ sodium pyruvate was pipetted into a vial containing $1 \mathrm{mg}$ beta-nicotinamide adenine dinucleotide $(1.28 \mu \mathrm{mol})$ and placed in a water bath at $37 \check{\mathrm{s}} \mathrm{C}$ for 5 minutes. Fifty microliters of the sample was then added. Exactly 30 minutes after adding the sample, the vials were removed from the water bath and placed at room temperature. One milliliter of 2,4-dinitrophenylhydrazine $(20 \mathrm{mg} / \mathrm{dl})$ in 1 $\mathrm{N}$ hydrochloric acid was added. Twenty minutes later, $10 \mathrm{ml}$ of $0.40 \mathrm{~N}$ sodium hydroxide was added to each vial. The samples were read against water at $450 \mathrm{~nm}$ with a spectrophotometer. A standard curve was prepared using various concentrations of sodium pyruvate corresponding to a range of LDH activities.

\section{Statistical Analysis}

Differences in water and ion contents between groups of rats were evaluated using analysis of variance and the Dunnett $t$-test or Student $t$-test where indicated. A probability value of less than 0.05 was used to indicate a significant difference. 
TABLE 1

RESULTS OF CEREBRAL BLOOD FLOW EXPER MENTS AFTER IN.ECTION OF VEH ILLE OR THROMBN IN 69 RATS*

\begin{tabular}{|c|c|c|c|c|c|c|c|}
\hline \multirow[b]{2}{*}{ Group } & \multicolumn{6}{|c|}{ Time After Infusion } & \multirow[b]{2}{*}{$24 \mathrm{Hrs}$} \\
\hline & 5 mins & 15 Mirs & 30 Wirs & 45 Mirs & $1 \mathrm{Hr}$ & $2 \mathrm{Hrs}$ & \\
\hline \multicolumn{8}{|l|}{ Vehicle $[n=21)$} \\
\hline $\begin{array}{l}\text { blood pressure } \\
\text { (mm Hg] }\end{array}$ & $103 \pm 2$ & $\mathrm{ND}$ & $105 \pm 5$ & $\mathrm{ND}$ & $104 \pm 4$ & $\mathrm{ND}$ & $96 \pm 2$ \\
\hline $\mathrm{pH}$ & $7.36 \pm 0.11$ & $\mathrm{ND}$ & $7.44 \pm 0.02$ & $\mathrm{ND}$ & $7.47 \pm 0.03$ & $\mathrm{ND}$ & $7.45 \pm 0.02$ \\
\hline $\begin{array}{l}\text { carbon doxide } \\
\text { [mm Hg] }\end{array}$ & $41.7 \pm 3.8$ & $\mathrm{ND}$ & $38.1 \pm 4.5$ & $\mathrm{ND}$ & $33.0 \pm 2.3$ & $\mathrm{ND}$ & $37.5 \pm 2.4$ \\
\hline ovgensat (\%) & $98.1 \pm 0.3$ & $\mathrm{ND}$ & $98.3 \pm 0.3$ & $\mathrm{ND}$ & $98.9 \pm 0.1$ & $\mathrm{ND}$ & $98.6 \pm 0.2$ \\
\hline $\begin{array}{l}\text { bicarbonate } \\
\text { (mmol'L) }\end{array}$ & $23.5 \pm 1.5$ & $\mathrm{ND}$ & $25.2 \pm 2.1$ & ND & $23.7 \pm 0.5$ & $\mathrm{ND}$ & $26 \pm 1.2$ \\
\hline hernatoctit (\%) & $40.3 \pm 0.3$ & $\mathrm{ND}$ & $43.0 \pm 1.9$ & $\mathrm{ND}$ & $40.0 \pm 0.0$ & $\mathrm{ND}$ & $40.0 \pm 0.4$ \\
\hline \multicolumn{8}{|c|}{ Trombin $(n=48)$} \\
\hline $\begin{array}{l}\text { blood pressure } \\
\text { [mm Ha] }\end{array}$ & $106 \pm 1$ & $101 \pm 1$ & $101 \pm 1$ & $103 \pm 7$ & $104 \pm 1$ & $100 \pm 0$ & $94 \pm 4$ \\
\hline $\mathrm{pH}$ & $7.47 \pm 0.02$ & $7.37 \pm 0.02$ & $7.42 \pm 0.02$ & $7.40 \pm 0.02$ & $7.45 \pm 0.03$ & $7.46 \pm 0.00$ & $7.44 \pm 0.02$ \\
\hline $\begin{array}{l}\text { carbon doxide } \\
\text { [mm Hg] }\end{array}$ & $37.0 \pm 1.8$ & $36.9 \pm 6.0$ & $43.6 \pm 3.0$ & $40.3 \pm 3.6$ & $39.5 \pm 3.8$ & $35.9 \pm 3.5$ & $35.8 \pm 1.5$ \\
\hline oxvensat & $98.4 \pm 0.2$ & $97.3 \pm 0.4$ & $97.8 \pm 0.4$ & $97.8 \pm 0.5$ & $98.2 \pm 0.3$ & $98.6 \pm 0.1$ & $98.0 \pm 0.6$ \\
\hline $\begin{array}{l}\text { ticarbonate } \\
\text { (mmolli) }\end{array}$ & $26.1 \pm 0.6$ & $21.2 \pm 3.1$ & $27.5 \pm 0.7$ & $24.8 \pm 1.6$ & $27.0 \pm 2.1$ & $25.6 \pm 2.0$ & $24.5 \pm 1.2$ \\
\hline hematootit (\%) & $41.0 \pm 0.5$ & $42.8 \pm 0.8$ & $40.4 \pm 0.5$ & $40.3 \pm 0.3$ & $41.4 \pm 0.6$ & $40.0 \pm 0.0$ & $42.0 \pm 0.6$ \\
\hline
\end{tabular}

\section{RESULTS}

\section{Cerebral Blood Flow}

The physiological parameters recorded during intracerebral infusion are shown in Table 1. Blood pressure, blood gas levels, and hematocrit values all remained within normal range.

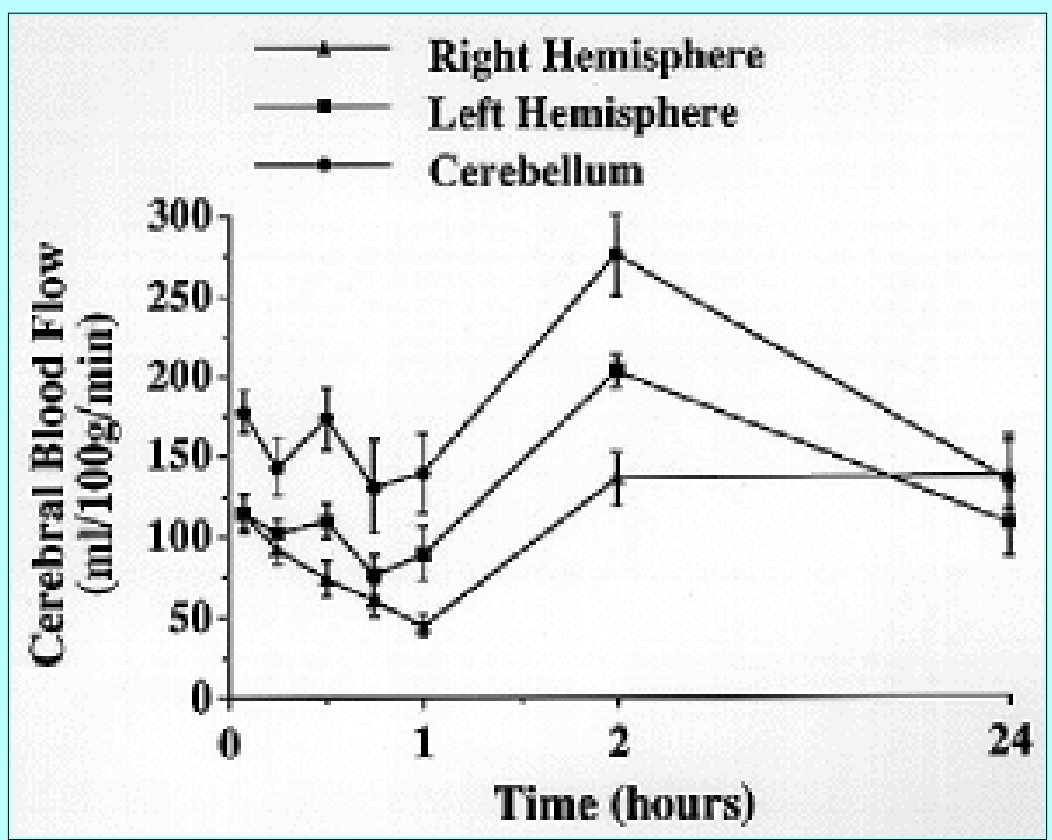

Fig. 1. Line graph showing cerebral blood flow in the hemispheres and cerebellum over time in rats receiving a $10-\mu \mathrm{l}$ injection of $10 \mathrm{U}$ thrombin into the right hemisphere. The values shown are means \pm standard errors of the means for 48 animals. 
Figure 1 demonstrates $\mathrm{CBF}$ in the right hemisphere over time in animals receiving an intracerebral injection of $10 \mu \mathrm{l}$ thrombin $(10 \mathrm{U})$. This quantity of thrombin was shown in previous studies to produce brain edema and is equivalent to the amount produced by a moderate-sized hematoma.[14,15] In the right hemisphere, left hemisphere, and cerebellum, blood flow declined over the 1st hour, rose to baseline or above by 2 hours, and then returned to baseline by 24 hours. The lowest blood flow recorded was $44.6 \pm$ $6.7 \mathrm{ml} / 100 \mathrm{~g} / \mathrm{minute}$ in the right hemisphere at 1 hour.

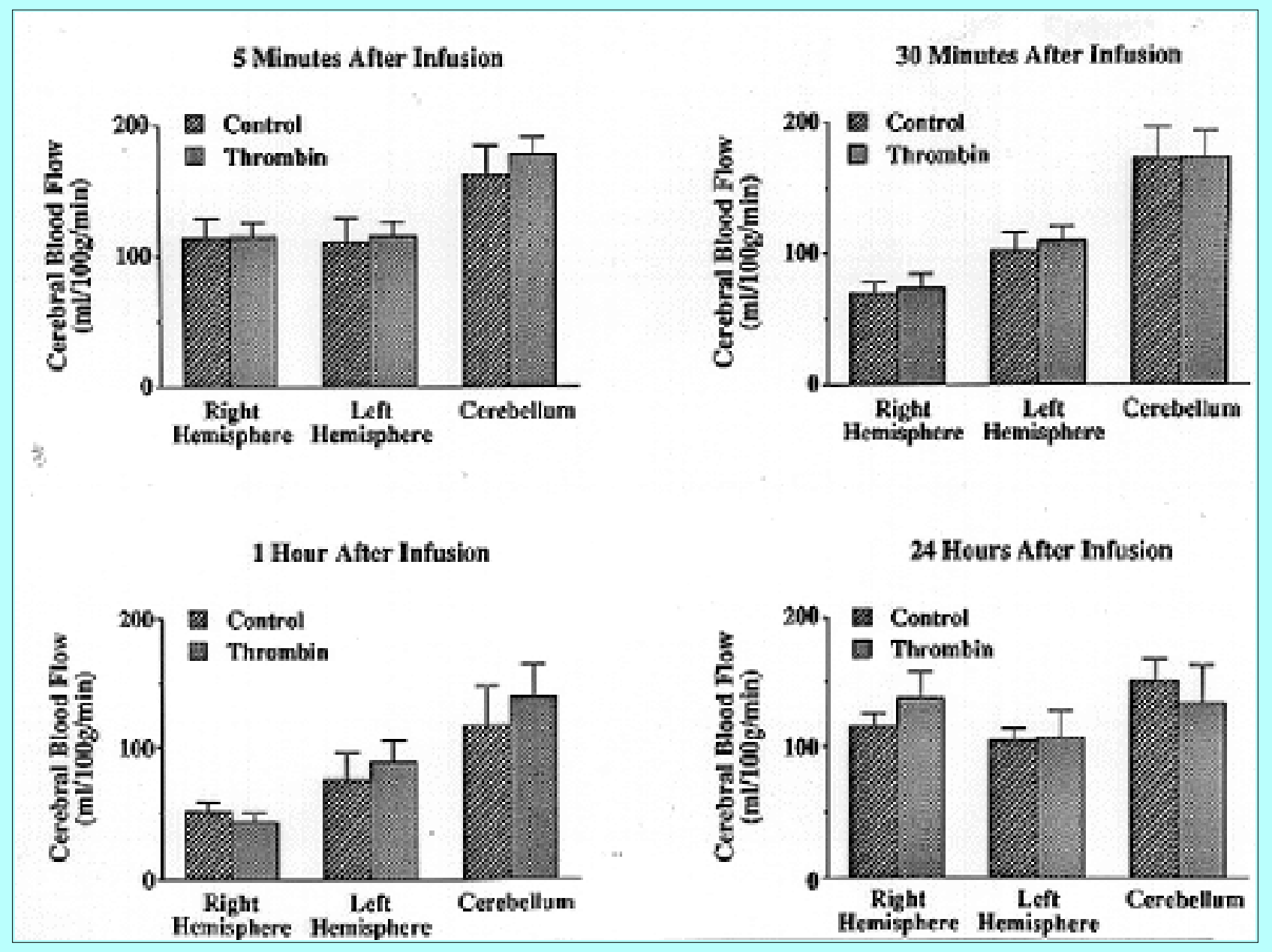

Fig. 2. Bar graphs comparing cerebral blood flow between control rats and groups receiving a $10-\mu \mathrm{l}$ injection of $10 \mathrm{U}$ thrombin into the right basal ganglia at various time points (5 minutes, 30 minutes, 1 hour, and 24 hours). The values shown are means \pm standard errors of the means for 21 control animals and 31 animals receiving thrombin. There were no significant differences between the control and thrombin-infused rats.

Figure 2 compares $\mathrm{CBF}$ among rats receiving an intracerebral injection of thrombin and groups receiving saline at 4 time points. There were no differences between these groups at any time point. The reduction in blood flow seen with thrombin infusion was also documented in the saline-infused animals. Because the reduction in $\mathrm{CBF}$ was similar between thrombin and saline groups no vasoactive role could be attributed to thrombin alone. Instead, it appears that the mechanical trauma from needle placement and infusion of solution resulted in a decrease in $\mathrm{CBF}$ that lasted approximately 1 to 2 hours. 


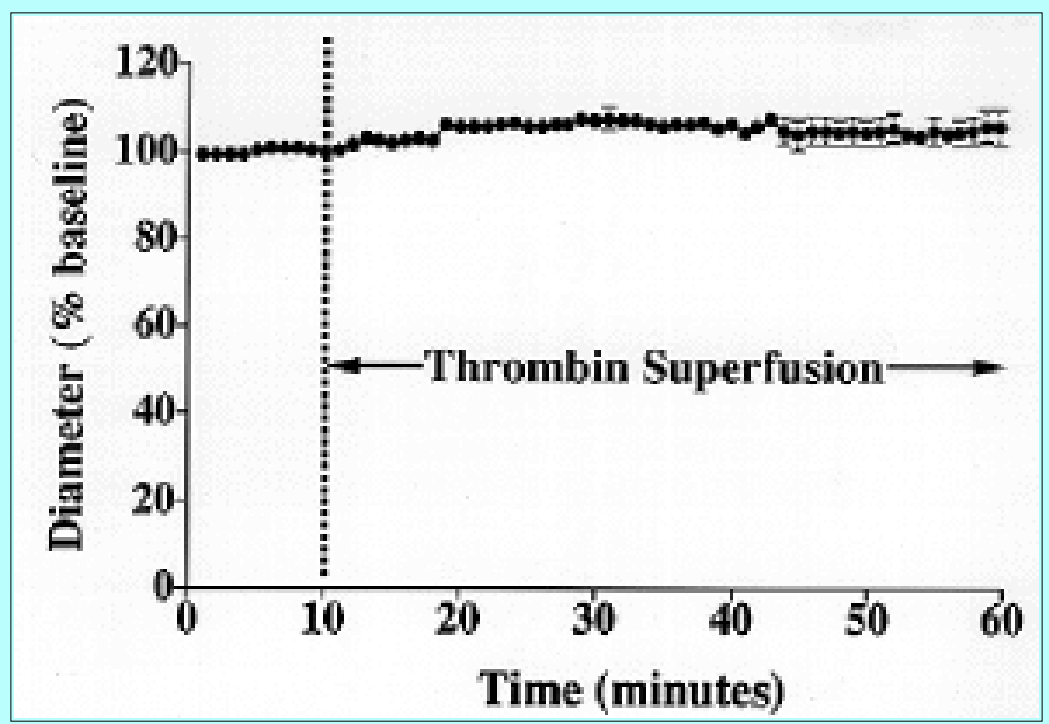

Fig. 3. Continuous time line showing microvessel diameter as a percentage of baseline in brain slices superfused with artificial cerebrospinal fluid for 10 minutes followed by 100 $\mathrm{U} / \mathrm{ml}$ of thrombin for 50 minutes. There was no change from baseline. The mean values \pm standard errors of the means for four experiments are shown.

\section{Microvessel Diameter}

Microvessel diameter was measured from in vitro brain slices superfused with thrombin. Experiments were performed using 0.1, 100, and $1000 \mathrm{U} / \mathrm{ml}$ of thrombin in the perfusate. Figure 3 shows the results at $100 \mathrm{U} / \mathrm{ml}$. Similar results were seen at the other concentrations of thrombin. There was no change in vessel size with exposure of the vessels to thrombin as compared to the baseline values recorded during perfusion of the microscope slide with artificial CSF.

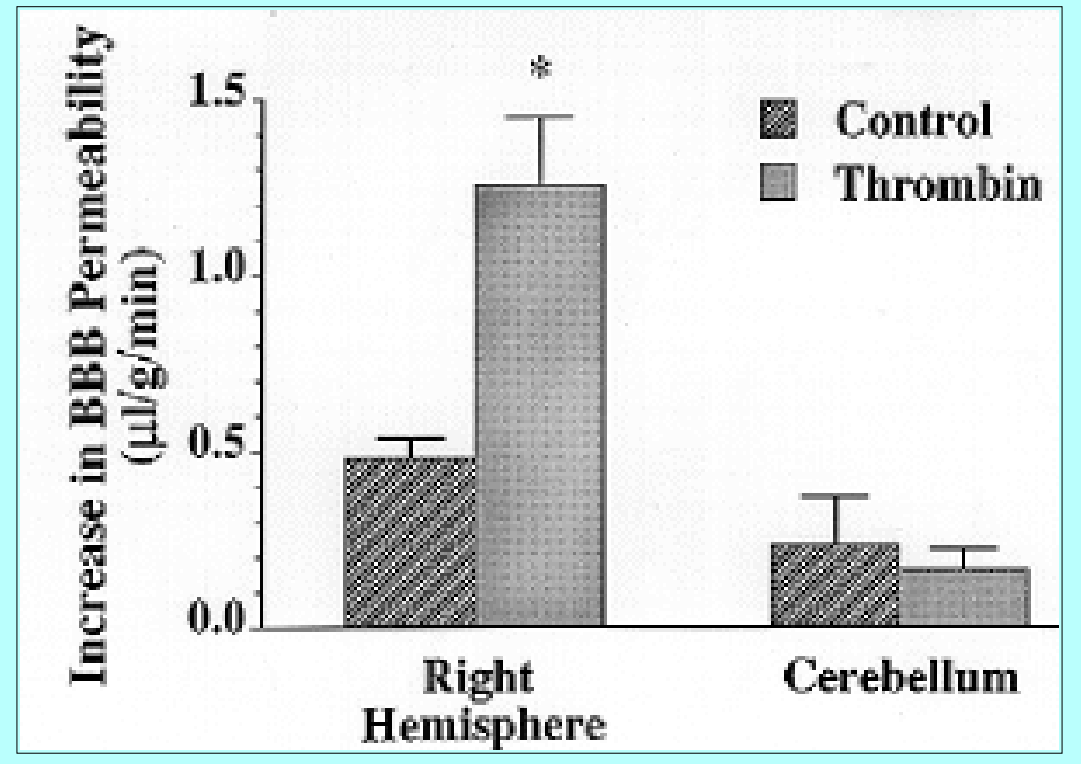

Fig. 4. Bar graph comparing blood-brain barrier (BBB) permeability to alpha-aminoisobutyric acid at 24 hours between control rats and groups receiving a $10-\mu \mathrm{l}$ injection of $10 \mathrm{U}$ thrombin. The values shown are means \pm standard errors of the means for six rats in each group. Asterisk indicates $p$ less than 0.05, control versus thrombin groups. The Student t-test was used for comparison. 
Figure 4 shows the increase in BBB permeability for AIB, which is a marker of BBB opening. The PS product (a factor proportional to BBB permeability and capillary vessel surface area) was calculated for each region of the brain. In these experiments vessel surface area was assumed to remain constant. The differences in PS product between the right and left sides in each rat were used to determine the increase in permeability.

Saline infusion caused a slight increase in AIB influx $(0.48 \pm 0.06 \mu \mathrm{l} / \mathrm{g} / \mathrm{minute})$, but thrombin infusion caused a much larger increase $(1.26 \pm 0.19 \mu \mathrm{l} / \mathrm{g} / \mathrm{min})$. These injections did not significantly affect the cerebellum. These values, therefore, indicate disruption of the BBB in the ipsilateral hemisphere due to thrombin.

\section{Brain Cell Toxicity}

Cell culture experiments were performed to determine whether thrombin has a direct toxic effect on brain cells. Figure 5 demonstrates the amount of LDH present in solutions containing C6 glioma cells exposed to various doses of thrombin for 24 hours. Because LDH is released from cells undergoing lysis, it is a marker of cell death. At a dose of $100 \mathrm{U} / \mathrm{ml}$ of thrombin there was an increase in LDH at 24, hours indicating a significant increase in cell death.

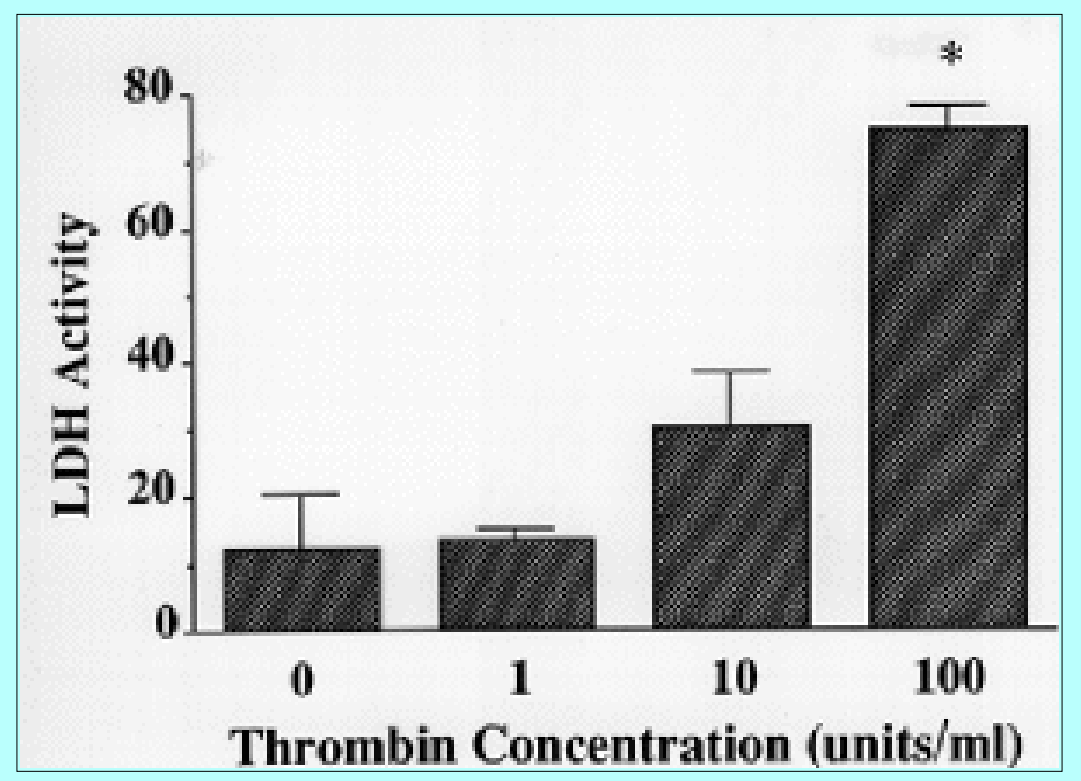

Fig. 5. Bar graph comparing lactate dehydrogenase (LDH) release from C6 glioma cells in cultures exposed to various concentrations of thrombin. The values shown are means \pm standard errors of the means in four experiments for each thrombin concentration. Asterisk indicates $\mathrm{p}$ less than 0.01 , control versus thrombin. The Dunnett t-test was used for comparison.

\section{DISCUSSION}

Cushing[5] believed that brain injury from ICH was due to local pressure compressing the microcirculation and producing ischemia in the region around a hematoma. Experimental studies have demonstrated CBF adjacent to an intracerebral hematoma does actually decrease. Cerebral blood flow in the rat falls below $25 \mathrm{ml} / 100 \mathrm{~g} /$ minute immediately adjacent to a hematoma.[3,19] The decline in CBF, however, resolves within 10 minutes.[21] The development of cerebral infarction is a function of both the degree and duration of ischemia; however, there is no experimental evidence that the degree or 
duration of hypoperfusion around an intracerebral hematoma is sufficient to produce ischemic cell damage. In monkeys, CBF below 10 to $12 \mathrm{ml} / 100 \mathrm{~g} /$ minute results in stroke only if sustained for 2 to 3 hours.[8] Blood flow greater than $23 \mathrm{ml} / 100 \mathrm{~g} /$ minute does not produce infarction, even with permanent ischemia. Thus, critical levels and durations of hypoperfusion have not been demonstrated immediately adjacent to a hematoma.

A global effect of the hematoma on CBF similarly does not explain the injury produced by most hematomas. An average-sized hematoma in humans $(54 \mathrm{ml})$ has little immediate effect on intracranial pressure or cerebral perfusion pressure because that volume is well within the volume-buffering capacity of the intracranial space.[10,20] Ischemia, therefore, is not initially the result of a global decline in perfusion pressure unless the mass is substantially greater than average.

There is evidence that intracerebral blood causes brain injury through biochemical substances released from the hematoma that initiate formation of brain edema.[16,17] Edema from an average-sized clot is mostly due to these biochemical substances and not to mass effect.[16,25] Recent studies of acute subdural hematomas have also implicated, but not identified, mediators of brain injury released from hematomas.[12,13]

Edema may be a marker of the severity of the initial brain injury as well as a contributor to subsequent injury. There is an increase in brain edema after ICH over the first 24 hours in rats receiving injections of $100 \mu \mathrm{l}$ of autologous blood into the basal ganglia.[32] Brain edema reaches a peak level and plateaus during the first 4 to 5 days after exposure of the brain to blood. Edema then begins to resolve. Brain ions, such as sodium and chloride, increase for 3 days and then begin to return to baseline levels. Potassium content decreases over 3 days due to its release from brain cells. The increase in total brain ions accounts for the majority of the osmolar force driving water into the brain.[32]

Thrombin, in amounts produced by clotted whole blood, causes changes in brain water and ion contents consistent with edema from an intracerebral hematoma.[14,15] Furthermore, the brain edema and ion changes due to intracerebral blood have been shown to be inhibited by thrombin inhibitors.

Our initial model for brain injury after ICH can be summarized as follows. Hemorrhage into the brain activates the coagulation cascade, which produces a large quantity of thrombin that, in turn, activates pathways that produce brain edema. Inactivation of thrombin by antithrombin III and other plasma inhibitors regulates brain edema. In addition, edema formation is attenuated by protease nexin-1, a thrombin inhibitor unique to the brain. The results of the current study further elucidate the mechanism of brain edema formation due to blood.

Throughout these studies the thrombin dose represented the amount of thrombin produced by a moderate-sized intracerebral hematoma. Because an average-sized intracerebral hematoma in humans contains approximately $1000 \mathrm{U}$ prothrombin,[24] a proportional hematoma in rats (50 $\mu \mathrm{l})$ has the potential to produce $10 \mathrm{U}$ thrombin.

Ischemia from inadequate $\mathrm{CBF}$ has not been shown to contribute to brain injury from either blood or thrombin in our model. Blood flow in the cerebral hemisphere was reduced to $50 \%$ of control at 1 hour after placement of a hematoma.[32] This level of flow was not below the ischemic threshold.[8] Cerebral blood flow returns to baseline by 4 hours, where it remains for the next 24 hours. No period of significant hypoperfusion was observed in these intracerebral hematoma experiments. Cerebral blood flow also decreased in the remaining brain, implicating a global mechanism of blood flow regulation in response to 
injury. Similar diffuse declines in CBF have also been shown in patients.

A similar blood flow time course was seen with thrombin infusion. Like blood, thrombin infusion did not produce periods of critically low CBF. In the ipsilateral hemisphere, CBF decreased approximately 50\% over the 1 st hour, never falling below the ischemic threshold. Within 2 hours of thrombin infusion, blood flow returned to baseline and maintained that level over the next 24 hours.

There were no differences in CBF between animals in the thrombin group and animals in the control group at multiple time points after infusion. The decline in $\mathrm{CBF}$ over the 1st hour after intracerebral infusion of blood, thrombin, and saline was likely due to the mechanical trauma of needle insertion and fluid infusion. A decrease in $\mathrm{CBF}$ with mechanical trauma is probably a homeostatic response to injury and not the primary cause of brain injury from ICH. This could explain the reduction in blood flow throughout the right hemisphere as compared to the left hemisphere in control animals receiving a right hemispheric injection of saline.

Numerous studies have shown that thrombin has vasoreactive properties.[1,6,7,31] These studies indicate that thrombin can produce both vasoconstriction and vasodilation, depending on the vascular bed and the species studied.

The effect of thrombin on the cerebral vasoreactivity was not significant in our study. Microvessels, acutely exposed to thrombin, showed no change in diameter over a period of 1 hour, suggesting that thrombin has no activity in small cerebral vessels $(<100 \mu \mathrm{m})$.

Blood-brain barrier permeability 24 hours after intracerebral hematoma placement was significantly increased in the ipsilateral hemisphere.[32] Infusion of thrombin produced the same amount of disruption of the BBB, suggesting that thrombin played a direct role in BBB breakdown. The large increase in BBB permeability contributed significantly to the total amount of edema fluid present in the brain.

The specific mechanism that leads to disruption of the BBB is unknown. Although a receptor-mediated pathway is possible, it is unlikely because recent studies of receptor localization have shown that the cloned thrombin receptor is absent from cerebrovascular endothelial cells.[30] Brain edema is seen with an intracerebral hematoma as early as 4 hours, whereas BBB disruption is not evident until later. The early brain edema, therefore, is not due to measurable BBB breakdown.

Our data indicate that injury to brain cells after ICH is due to cytotoxicity from thrombin. Because ischemia is a product of both $\mathrm{CBF}$ and cerebral metabolic rate, a disorder in either parameter may lead to brain injury. The direct cell toxicity of thrombin, in amounts produced by an average-sized intracerebral hematoma, appears to produce cell damage through metabolic disruption as opposed to impairment of blood flow.

Recently, low doses of thrombin have been shown by Vaughan and coworkers[27] to be protective of brain cells subjected to environmental stresses such as hypoglycemia or hydrogen peroxide. They have demonstrated that activation of the thrombin receptor on neurons and glia with low levels of thrombin prevents cell death. Their data also indicate that at higher doses of thrombin brain cells are damaged. In our study, C6 glioma cells, which are cytologically similar to glia,[9] were disrupted by levels of thrombin that are typically produced by a blood clot. The exact receptor or zymogen activated by thrombin that produces cell death is unknown; however, this process is probably not mediated by the same receptor that affords cell protection. 
Cerebral metabolism adjacent to a hematoma increases in rat models of intracranial hemorrhage.[12] There is an increase in cerebral metabolism with a simultaneous reduction in regional CBF adjacent to a hematoma, indicating uncoupled flow and metabolism. This harmful effect of blood is mediated through $\mathrm{N}$-methyl-d-aspartate (NMDA) receptors. Ischemic cell damage due to intracranial blood can be inhibited by NMDA antagonists. [4,13] High concentrations of excitatory amino acids may exacerbate ischemic damage through an "excitotoxic" mechanism. This direct cell toxicity may be mediated by the large amount of thrombin released from hematomas. The primary event leading to brain injury and edema following ICH therefore appears to be blood-induced metabolic disruption initiated by a substance such as thrombin that diffuses from the hematoma into the brain. A metabolic insult leads to ischemic necrosis even in the presence of CBF levels that are not below the usual ischemic threshold.

\section{CONCLUSIONS}

Brain injury and edema from an intracerebral hematoma appear to be due to thrombin that is produced by the coagulation cascade. Although some degree of reduction in local CBF occurs, ischemic levels are not present. Early edema is due to direct cell toxicity, possibly mediated through a cytotoxic receptor or zymogen activated by thrombin. An excitotoxic pathway may lead to cell injury. Later, breakdown of the BBB contributes to edema formation.

\section{References}

1. Bacic F, Uematsu S, McCarron RM, et al: Secretion of immunoreactive endothelin-1 by capillary and microvascular endothelium of human brain. Neurochem Res 17:699-702, 1992

2. Blasberg RG, Fenstermacher JD, Patlak CS: Transport of alpha-aminoisobutyric acid across brain capillary and cellular membranes. J Cereb Blood Flow Metab 3:8-32, 1983

3. Bullock R, Mendelow AD, Teasdale GM, et al: Intracranial haemorrhage induced at arterial pressure in the rat. Part 1. Description of technique, ICP changes and neuropathological findings. Neurol Res 6:184-188, 1984

4. Chen MH, Bullock R, Graham DI, et al: Ischemic neuronal damage after acute subdural hematoma in the rat: effects of pretreatment with a glutamate antagonist. J Neurosurg 74:944-950, 1991

5. Cushing H: Some experimental and clinical observations concerning states of increased intracranial tension. Am J Med Sci 124:375-400, 1902

6. Delin A, Olsson P, Teger-Nilsson AC: Vasodilatation in the canine leg caused by intraarterial infusion of thrombin and tissue thromboplastin. Cardiovasc Res 1:371-378, 1967

7. Glusa E: Vascular effects of thrombin. Semin Thromb Hemost 18:296-304, 1992

8. Jones TH, Morawetz RB, Crowell RM, et al: Thresholds of focal cerebral ischemia in awake monkeys. J Neurosurg 54:773-782, 1981

9. Kempski O, Staub F, Schneider GH, et al: Swelling of C6 glioma cells and astrocytes from glutamate, high K+ concentrations or acidosis. Prog Brain Res 94:69-75, 1992

10. Kingman TA, Mendelow AD, Graham DI, et al: Experimental intracerebral mass: description of model, intracranial pressure changes and neuropathology. J Neuropathol Exp Neurol 47:128-137, 1988 
11. Koh JY, Choi DW: Quantitative determination of glutamate mediated cortical neuronal injury in cell culture by lactate dehydrogenase efflux assay. J Neurosci Meth 20:83-90, 1987

12. Kuroda Y, Bullock R: Failure of cerebral blood flow-metabolism coupling after acute subdural hematoma in the rat. Neurosurgery 31:1062-1071, 1992

13. Kuroda Y, Inglis FM, Miller JD, et al: Transient glucose hypermetabolism after acute subdural hematoma in the rat. J Neurosurg 76:471-447, 1992

14. Lee KR, Betz AL, Keep RF, et al: Intracerebral infusion of thrombin as a cause of brain edema. J Neurosurg 83:1045-1050, 1995

15. Lee KR, Betz AL, Kim S, et al: The role of the coagulation cascade in brain edema formation after intracerebral hemorrhage. Acta Neurochir 138:396-401, 1996

16. Lee KR, Colon GP, Betz AL, et al: Edema from intracerebral hemorrhage: the role of thrombin. J Neurosurg 84:91-96, 1996

17. Lee KR, Keep RF, Betz AL, et al: A thrombin antagonist, hirudin, inhibits brain edema formation in a model of intracerebral hemorrhage, in Nagai H, Kamiya K, Ishii S (eds): Intracranial Pressure IX. Tokyo: Springer-Verlag, 1994, pp 70-75

18. Maier-Hauff K, Baethmann AJ, Lange M, et al: The kallikrein-kinin system as mediator in vasogenic brain edema. Part 2: Studies on kinin formation in focal and perifocal brain tissue. $\mathbf{J}$ Neurosurg 61:97-106, 1984

19. Mendelow AD, Bullock R, Teasdale GM, et al: Intracranial haemorrhage induced at arterial pressure in the rat. Part 2: Short term changes in local cerebral blood flow measured by autoradiography. Neurol Res 6:189-193, 1984

20. Nath FP, Jenkins A, Mendelow AD, et al: Early hemodynamic changes in experimental intracerebral hemorrhage. J Neurosurg 65:697-703, 1986

21. Nath FP, Kelly PT, Jenkins A, et al: Effects of experimental intracerebral hemorrhage on blood flow, capillary permeability, and histochemistry. J Neurosurg 66:555-562, 1987

22. Paxinos G, Watson C: The Rat Brain in Stereotaxic Coordinates. Sydney: Academic Press, 1982

23. Sagher O, Zhang XQ, Szeto W, et al: Live computerized videomicroscopy of cerebral microvessels in brain slices. J Cereb Blood Flow Metab 13:676-682, 1993

24. Seegers WH: Prothrombin. Cambridge, Mass: Harvard University Press, 1962, pp 417-443

25. Sinar EJ, Mendelow AD, Graham DI, et al: Experimental intracerebral hemorrhage: effects of a temporary mass lesion. J Neurosurg 66:568-576, 1987

26. Van Uitert RL, Levy DE: Regional brain blood flow in the conscious gerbil. Stroke 9:67-72, 1978

27. Vaughan PJ, Pike CJ, Cotman CW, et al: Thrombin receptor activation protects neurons and astrocytes from cell death produced by environmental insults. J Neurosci 15:5389-5401, 1995 
28. Volpin L, Cervellini P, Colombo F, et al: Spontaneous intracerebral hematomas: a new proposal about the usefulness and limits of surgical treatment. Neurosurgery 15:663-666, 1984

29. Wagner RH, Graham JB, Penick GD, et al: Estimation of prothrombin by the two-stage method, in Tocantins LM, Kazal LA (eds): Blood Coagulation, Hemorrhage, and Thrombosis. Methods of Study. New York: Grune \& Stratton, 1955, pp 159-164

30. Weinstein JR, Gold SJ, Cunningham DD, et al: Cellular localization of thrombin receptor mRNA in rat brain: expression by mesencephalic dopaminergic neurons and codistribution with prothrombin mRNA. J Neurosci 15:2906-2919, 1995

31. White RP: Comparison of the inhibitory effects of antithrombin III, alpha2-macroglobulin, and thrombin in human basilar arteries: relevance to cerebral vasospasm. J Cereb Blood Flow Metab 7:68-73, 1987

32. Yang GY, Betz AL, Chenevert TL, et al: Experimental intracerebral hemorrhage: relationship between brain edema, blood flow, and blood-brain barrier permeability in rats. J Neurosurg 81:93-102, 1994

Manuscript received June 26, 1996.

Accepted in final form September 16, 1996.

This work was supported by Grant Nos. NS-17760 and NS-23870 from the National Institutes of Health. Address reprint requests to: Kevin R. Lee, M.D., Department of Neurological Surgery, Wayne State University, 6E UHC, 4201 St. Antoine, Detroit, Michigan 48201.

Click here to go to Editorial Perspective on Article 1. 